\title{
The Relationship of Academic Self-Regulation with Self-Esteem and Goal Orientations Among University Students in Jordan
}

\author{
Abdalmuhdi M. Sawalhah ${ }^{1} \&$ Asaad Al Zoubi ${ }^{2}$ \\ ${ }^{1}$ Irbid National University, Irbid, Jordan \\ 2 The University of Jordan, Jordan \\ Correspondence: Abdalmuhdi M. Sawalhah, Irbid National University, Irbid, Jordan.
}

Received: March 12, 2019

doi:10.5539/ies.v13n1p111
Accepted: October 29, $2019 \quad$ Online Published: December 30, 2019

URL: https://doi.org/10.5539/ies.v13n1p111

\begin{abstract}
This study aimed at identifying the level of each of the academic self-regulation and self-esteem, and goal orientations; and identifying the gender differences in each variable, as well as identifying the relationship between academic self-regulation and self-esteem, and goal orientations. The sample of the study consisted of 463 students from Irbid National University. The results of the study revealed that the sample of the study showed a medium level in each of the academic self-regulation and self-esteem, and goal orientations as a whole and of each of its dimensions, and the existence of gender differences in the two scales of academic self-regulation and self-esteem in the favor of females, while in the goal orientations the gender differences were in the two dimensions: mastery-approach, performance-avoidant in the favor of females, and performance-approach domain in the favor of males. The results also indicated a statistically significant positive relationship between academic self-regulation and of each of the self-esteem, and goal orientations.
\end{abstract}

Keywords: academic self-regulation, self-esteem, goal orientations, gender differences, university students, Jordan

\section{Introduction}

The level of education in university education occupies a large part of the attention of educational researchers, they try to identify the reasons and factors that help to achieve better results in this area; perhaps the academic self-regulation is one of the most important things that help the learner to improve his level on the one hand, on the other hand, he works on self-improvement, appreciation and motivation development that directs behavior towards specific goals in order to reach the best levels of academic performance and the acquisition of information and skills.

Baumeister and Vohs (2007) argue that academic self-regulation is the ability of an individual to change his behavior. The behaviors that change according to some criteria and ideals or goals that arise from internal or societal expectations, Zimmerman (2000) believes that academic self-regulation increases the degree of flexibility and adaptive capacity in the learning environment. Academic self-organization helps to ensure the individual's status in the social conscience at the expense of his selfish motives to the extent that individuals are doing what is right and it is not what they want to do, it prevents the individual from indulging in harmful motives (Baumeister \& Bushman, 2008). Zimmerman (2000) argues that academic self-regulation is inevitable in order to survive, which ensures social acceptance within the educational environment. Academic self-regulation is an indicator of healthy life, associated with success or failure in many aspects of educational life (Baumeister \& Vohs, 2004).

Sayette (2004) classifies the failure of self-organization into two types: 1) Within the organization, this means a total failure of the organization itself; 2) in poorly organized means to exercise control in a way that does not achieve the desired results. Therefore, Baumeister and Vohs (2007) emphasized that individuals who have an aptitude for academic self-organization in general are successful individuals in the school, work, relationships, and have positive psychological health. And that self-organization is divided into four main elements below:

Standards: Since self-regulation is a change in an individual's behavior according to idealism, goals or demands that arise from internal or societal expectations, it occurs when individuals think that their changes do not meet these standards and therefore their behavior should be regulated to meet these criteria so that these criteria are clear for effective self-regulation (Baumeister \& Bushman, 2008). 
Monitoring: As self-regulation is a periodic process that uses feedback to perform in advance to make adjustments during current efforts, and therefore it is necessary to follow behaviors to achieve efficiency in self-organization (Baumeister \& Vohs, 2007).

The power of self-organization: Which is known as will power; Self-change is not easy, it requires strength and will, each individual has a certain reservoir of willpower. When this resource is depleted, self-regulation decreases (Schmeichel \& Baumeister, 2004).

Motivation: Motivation is an integral part of self-organization even if the other components are combined as clarity of standards, effective control, and strong will of organization. But all components must be present for the success of self-organization (Baumeister \& Vohs, 2007).

Self-esteem continues to persist in youth and middle age; it then begins to decline gradually until the old age based on changes and differences in the area of health, cognitive ability and socioeconomic status of the individual, while no gender differences were found in the development of self-esteem or social changes such as educational grade inflation (Orth \& Robbins, 2014).

When a learner loses his organization in his academic life, he loses motivation to learn and becomes an inactive individual because of the lack of planning and the setting of goals that seek to achieve. The goal orientation is seen as acting toward developing or demonstrating capacity in achievement situations, and is considered to be a variable of motivation to use climate, performance assessment and selection, and performance trends can predict individual performance, goal setting, learning and adaptive behaviors in training, education and leadership (DeGeest \& Brown, 2011). The goal orientations are defined as cognitive representations of the things we seek to accomplish, which guide us and to provide the energy of behavior and determine our attitudes (Harackiewicz, Barron, \& Elliot, 1998) While Ames (1992) defined it as an integrated system of beliefs, interpretations and sentiments that constitute the goals and purpose of the behavior and is to engage in and respond to the work and activities of achievement.

Dweck proposed two types of goal orientations: learning orientations and performance orientations the orientations of the learning goals are called the orientations of the goals of mastery and are close to situations that seek to develop the individual's abilities through acquiring new skills and mastering the new situations, and do not care about their performance for others. Performance targets are closer to those that seek the approval of colleagues and teachers, seeking to prove and verify the adequacy of competence in order to obtain favorable judgments and avoid negative judgments (Hendricks \& Payne, 2007).

Fan, Meng, Billings, Litchfield, and Kaplan (2008) point to the relationship between learning goal orientation and goal setting and self-efficacy. Individuals with learning orientation and high self-efficacy are set high goals. Payne et al. (2007) points out that the dimensions of goal orientations are strongly related to structures of self-organization, especially self-efficacy, meta-knowledge and feedback, in terms of performance structures, they relate to academic and organizational performance. Goal orientation is the behavioral tendency of individuals to achieve achievement in tasks. The attitudes of positive learning goals are linked to self-organizing behaviors such as planning and goal setting, which are linked to academic performance. Individuals with higher levels of learning goal orientation are subject to good performance in academic assignments. The researcher sees that the relationship between the variables of the study is mutual. Abu Ghazal, Hamouri, and Ajlouni (2013) indicate that there is an inverse relationship between the performance orientation and the performance orientation-avoidance on the one hand and self-esteem, and a direct relationship between the direction of perfection-self-esteem, Panadero and Alonso-Tapia (2014) pointed out that individuals with high self-esteem have the ability to remember and are motivated to learn, possess self-organizing learning strategies, and have a high ability to take responsibility for their learning.

\subsection{The Problem of the Study and Its Questions}

The researcher noted that the lack of self-regulation in the academic life of university students plays an important role in the weakness of their access to the required level of self-esteem, in addition to the differences between the students in the direction of the goals and weak motivation. The researcher believes that the academic self-organization did not receive the attention of Arab researchers, and the lack of Arab studies that dealt with this variable.

Hence the problem of the current study is to reveal the relationship of self-regulation academic self-esteem and goal orientations in a sample of university students in Jordan. In light of the above, the present study seeks to answer the following questions:

1) What is the level of (academic self-regulation, self-esteem, goal orientation) among a sample of university 
students in Jordan?

2) Are there statistically significant differences in the level of academic self-regulation, self-esteem, goal orientation (due to gender variable in a sample of university students in Jordan?

3) Is there a statistically significant relationship between academic self-organization and self-esteem and goal orientations among a sample of university students?

\subsection{Objectives of the Study}

The present study aims to achieve the following objectives: the detection of the level of academic self-regulation, self-esteem, and goal orientations among a sample of university students in northern Jordan, and to identify the differences between the grades of university students on the scale of each of the academic self-regulation, self-esteem, and goal orientations according to gender variable (male, female). And to identify the statistical relationship between academic self-organization and self-esteem and goal orientations in the study sample.

\subsection{The Importance of the Study}

The importance of the study comes from the importance of the subject of academic self-organization, which did not receive the attention of educators and researchers at the Arab level. The results of this study may contribute to helping educators and teachers to provide students with self-organizing ways of their academic life, therefore, this study may provide a theoretical framework that helps to increase the level of understanding of the nature of academic self-regulation among high school students, and provide the supervisors in the schools with information related to academic self-regulation, and develop successful solutions to raise self-esteem and help guide the goals, and thus the possibility of building plans and programs guidance and submit it to students to contribute to achieve the best academic level.

\subsection{Procedural Definitions}

Academic self-regulation: is the process of controlling the individual and evaluating the learning behaviors of the educational situations, and regulating the actions towards the goals of acquiring information and experiences and expanding and improving the self (Ormrod \& Jones, 2009), it is defined procedurally as the degrees that the students obtain on the scale used in this study, which is prepared by the researcher.

Self-esteem: is a personal trait of self-description or personal worth, which involves a range of beliefs, emotions and behaviors (Branden, 2001), it is defined procedurally as the degree that the students obtain on the scale used in Jaradat's (2006) study.

Goal orientations: behaviors that seek to develop and demonstrate the ability to achieve, which predict performance in different situations, goal setting, learning and adaptive behaviors in training (DeGeest \& Brown, 2011), it is defined procedurally by the degree that the students obtain on the scale used in the study of Abu Ghazal et al. (2013).

\subsection{The limits of the Study}

1) The temporal limit: the second semester of the academic year 2017-2018.

2) Spatial Limit: The city of Irbid in northern Jordan.

3) Institutional Limit: Irbid National University in Northern Jordan.

4) Human Limit: Irbid National University students (males, females).

\section{Previous Studies}

Collison, Banbury, and Lusher (2016) conducted a study aimed at identifying self-esteem in a sample of university students in the light of some variables. The study sample consisted of 100 male and female students. The results of the study showed that self-esteem is higher among males than females, and there is a negative correlation between age and self-esteem.

Sarmini (2015) study aimed to reveal the relationship between the goals and the five factors of the personality and the sample of the study consisted of 639 students of Yarmouk University students. The results of the study showed that the most common goal orientation in the students was performance, and there were statistically significant differences in the performance orientation in favor of the males. The results did not show any significant differences in both the orientation of the mastery and the avoidance due to the gender variable.

Abu Ali (2015) study which aimed to know the relationship between the goals and Meta cognitive thinking of students at Yarmouk University, The study sample consisted of 759 male and female students. The results of the study showed that the mastectomy is the most common orientation, followed by a performance-oriented approach, 
followed by a performance-avoidance approach; the results showed statistically significant differences in the mastery orientation due to the effect of gender variable in favor of males, and the absence of statistically significant differences in the performance dimension and avoidance dimension due to the impact of gender variable.

H. Kaur and K Kaur's (2014) study identifies gender differences in terms of strengths, perceptions and difficulties and the ability to the academic self-organization, the study sample consisted of 100 adolescents. The results showed that there were no gender differences among the sample of the study on the academic self-regulation scale as well as on the strengths and difficulties points.

In the study of Abu Ghazal et al. (2013) which aims to determine the relationship between the goals orientation with self-esteem and academic procrastination, the sample of the study consisted of 641 students from Yarmouk University students. The results of the study revealed a significant inverse relationship between the performance orientation and avoidance orientation from one hand and self-esteem from another hand, and the positive relationship between the mastery orientation and self-esteem. The results revealed significant differences in the relationship between the mastery orientation and self-esteem in favor of males, the results showed that there are significant differences in the strength of the relationship between the performance-avoidance and self-esteem trend for females.

Akhtar and Mahmood's (2013) study collected psychological information related to the development of the academic self-regulation scale, the study sample consisted of (410) university students. The results of the study showed that there is a scale of (30) paragraphs measuring five dimensions: self-planning, self-monitoring, self-learning, self-evaluation and self-reaction, the results also showed high internal consistency.

The study of Sakiz (2011) aimed to identify the goal orientations and their relation to the beliefs of academic effectiveness and the behavior of the request for academic assistance to students of a Turkish university. The study sample consisted of (98) male and female students. The results of the study showed that the goal-oriented approach was positively and statistically linked to the beliefs of academic self-efficacy and behavior. The results also indicated that the performance-oriented approach was not statistically linked to the beliefs of academic self-efficacy and student behavior.

Johnson, Radosevich, and Radosevich (2009) conducted a study aimed at investigating the goal of self-assessment of the goals and cognitive learning strategies. The study sample consisted of 228 university students. The results of the study showed a positive relationship between the objectives of learning and self-esteem, and the relation between the goals of performance- avoidance and self-esteem, and a relationship between the objectives of performance and self-esteem.

\section{Method and Procedures}

The study used the descriptive correlative approach in the research. The study attempted to identify the relationship between self-regulation and self-esteem, and the goals orientations, and whether this relationship differs according to gender.

\subsection{Population of the Study}

The study population consists of all students at the Irbid National University of both sexes (male and female) for the academic year 2016-2017, and enrolled in the second semester and their number reached (1300) students.

\subsection{Sample of the Study}

The sample of the study consisted of 463 students who were selected in a cluster random manner, reaching $36 \%$.

Table 1 shows the distribution of sample members.

Table 1. Distribution of sample members

\begin{tabular}{cccc}
\hline Variable & Level & $\mathrm{N}$ & percentage \% \\
\hline \multirow{4}{*}{ Gender } & Male & 251 & 54.2 \\
& Female & 212 & 45.8 \\
& Total & 463 & $100 \%$ \\
\hline
\end{tabular}

\subsection{Study Tools}

\subsubsection{First: The Scale of Academic Self-Regulation}

The researcher reviewed the previous theoretical literature and previous studies related to academic 
self-regulation, such as the study of Sahloul (2009), Akhtar and Mahmood (2013), H. Kaur, and K. Kaur (2014) and Sarmini (2016), in order to prepare the scale of academic self-regulation.

\subsubsection{Validity of the Scale}

The researcher verified the content validity by presenting the scale after its translation into Arabic on a group of arbitrators numbering 8 arbitrators with specialization in education and psychology at Irbid National University, in order to ascertain the extent to which the scale items of this category of students whom the study will be applied on them, where the arbitrators unanimously agreed on the paragraphs with a percentage of $80 \%$, this proportion is reliable for the study. The researcher also extracted the construction validity of the scale by applying it to a sample of 48 students from outside the study sample. Therefore, the values of correlation coefficients for paragraphs were calculated with the scale as a whole. Table 2 shows this.

Table 2. Correlation coefficient values (corrected) for the self-regulation academic scale

\begin{tabular}{|c|c|c|c|c|c|c|c|c|c|}
\hline $\mathrm{N}$ & $\begin{array}{l}\text { Correlation } \\
\text { Coefficient }\end{array}$ & $\mathrm{N}$ & $\begin{array}{l}\text { Correlation } \\
\text { Coefficient }\end{array}$ & $\mathrm{N}$ & $\begin{array}{l}\text { Correlation } \\
\text { Coefficient }\end{array}$ & $\mathrm{N}$ & $\begin{array}{l}\text { Correlation } \\
\text { Coefficient }\end{array}$ & $\mathrm{N}$ & $\begin{array}{l}\text { Correlation } \\
\text { Coefficient }\end{array}$ \\
\hline 1 & 0.79 & 8 & 0.62 & 15 & 0.83 & 22 & 0.86 & 29 & 0.89 \\
\hline 2 & 0.57 & 9 & 0.48 & 16 & 0.73 & 23 & 0.75 & 30 & 0.53 \\
\hline 3 & 0.68 & 10 & 0.54 & 17 & 0.65 & 24 & 0.56 & 31 & 0.69 \\
\hline 4 & 0.84 & 11 & 0.61 & 18 & 0.80 & 25 & 0.52 & 32 & 0.59 \\
\hline 5 & 0.66 & 12 & 0.93 & 19 & 0.78 & 26 & 0.82 & & \\
\hline 6 & 0.90 & 13 & 0.70 & 20 & 0.65 & 27 & 0.74 & & \\
\hline 7 & 0.83 & 14 & 0.59 & 21 & 0.51 & 28 & 0.63 & & \\
\hline
\end{tabular}

It is noted from the data in Table 2 that the values of correlation coefficients of the scale items ranged from 0.48 to 0.93 , all of which are statistically significant.

\subsubsection{Reliability of the Scale}

The researcher verified the reliability of the scale in two ways: the first by applying it to a survey sample of 48 students. The coefficient of internal consistency was calculated as alpha Cronbach for the dimensions. The reliability value was 0.88 ; the second method was stability of the reliability by applying it to the same survey sample. It was re-applied two weeks after the first application, with a reliability value of 0.91 .

\subsubsection{Correction of the Scale}

The scale consists of 32 paragraphs consisting of a quadratic scale $(1=$ not applicable at all, $2=$ does not apply to, $3=$ applies somewhat, $4=$ applies to me strongly), and ranges from 32 to 128 where higher grades indicates higher academic self-regulation.

\subsubsection{Second: Rosenberg's Scale of Self-Esteem}

The study examined the literature and previous studies on self-esteem, such as the study of Jaradat (2006), the cross-section of the Rosenberg (1965), the study of Collison et al. (2016), Shabaily and Al-Watban (2016), and S. Kapikiran and N. Kapikiran (2016), the researcher considered that it is better to use the scale used in the study of Jaradat (2006).

\subsubsection{Validity of the Scale}

Jaradat (2006) translated the scale into Arabic and presented it to specialists in the field of counseling and psychology at Yarmouk University to review the translation and the linguistic wording of the paragraphs. The text of 4 paragraphs of the scale was amended. And the arbitrators agreed with a percent of $40 \%$ that all paragraphs are appropriate, thus, the number of paragraphs remained as they were in the original scale. In the present study, the researcher verified the validity of the content by presenting the scale in its original form to a group of arbitrators of 8 arbitrators with specialization in education and psychology at Irbid National University, to ascertain the suitability of the scale paragraphs for this category of students to whom the study will be applied on, where the arbitrators unanimously agreed on the paragraphs by $75 \%$. This percentage is reliable for conducting the study. The researcher also extracted the construction validity of the scale by applying it to a sample of 48 students from outside the study sample. Therefore, the values of correlation coefficients for paragraphs were calculated with the scale as a whole, as shown in Table 3. 
Table 3. Correlation coefficient values (corrected) for the self-assessment scale paragraphs

\begin{tabular}{cccccc}
\hline $\mathrm{N}$ & $\begin{array}{r}\text { Correlation } \\
\text { Coefficient }\end{array}$ & $\mathrm{N}$ & $\begin{array}{r}\text { Correlation } \\
\text { Coefficient }\end{array}$ & $\mathrm{N}$ & Correlation Coefficient \\
\hline 1 & 0.66 & 5 & 0.65 & 9 & 0.83 \\
2 & 0.57 & 6 & 0.63 & 10 & 0.52 \\
3 & 0.54 & 7 & 0.78 & & \\
4 & 0.62 & 8 & 0.69 & & \\
\hline
\end{tabular}

It is noted from the data in Table 3 that the values of the correlation coefficients of the scale items ranged between 0.52 and 0.83 , all of which are statistically significant values. The researcher adopted a criterion for accepting the paragraph that its correlation coefficient with the dimension and the list as a whole is not less than 0.30 .

\subsubsection{Reliability of the Scale}

Jaradat (2006), according to the coefficient of internal consistency, the Cronbach alpha formula was applied to the scores of the sample, where the value of consistency coefficients $(0.73)$. The current study investigated the reliability of the scale in two ways: The first was through its application to a survey sample of 48 students. The coefficient of internal consistency was calculated using alpha Cronbach for dimensions, with a reliability value of (0.83). The second method was the reliability of stability applied to the same survey sample. It was re-applied two weeks after the first application. The reliability value was 0.87 .

\subsubsection{Correction of the Scale}

The scale consists of (10) paragraphs consisting of a quadratic graduation $(1=$ strongly agree, $2=\mathrm{I}$ agree, $3=$ disagree, $4=$ strongly disagree $)$, and in the opposite paragraphs $(1,3,4,7,10)(4=$ Strongly Agree, $3=$ Agree, $2=$ Disagree, $1=$ Strongly Disagree), and the grades range from 10 to 40 so that the higher scores indicate a higher estimate.

\subsubsection{Third: The Scale of Oriented Targets}

The researcher looked at previous literature and studies related oriented targets, such as Lindsay and Scott (2005), Matuge (2009), Abu Ali (2015), Abu Ghazal et al. (2013) the researcher found it better to use the scale used in the study of Abu Ghazal et al. (2013).

\subsubsection{Validity of the Scale}

Abu Ghazal et al. (2013) presented the scale in its initial form, consisting of 25 items on 5 arbitrators specialized in the field of educational psychology at Yarmouk University, and asked them to indicate the extent of belonging of the paragraphs to the dimension which it belongs to, and the clarity of the items and the integrity of the language, according to their views, 4 items were deleted to become a scale consisting of 21 items. They also used the factorial analysis. The degree of saturation of the mastery dimension ranged between 0.00 and 0.75 and the performance dimension ranged between 0.04 and 0.73 . After the avoidance-performance dimension, the saturation degree ranged between 0.03 and 0.70 .

As for the current study, the researcher verified the content validity by presenting the scale in its original form to a group of arbitrators of 8 arbitrators specialized in education and psychology at the Irbid National University to ascertain the suitability of the scale items for this category of students. , Where the judges agreed on the items by $80 \%$, this proportion is reliable for the study. The researcher also extracted the construction validity of the scale by applying it to a sample of 48 students from outside the study sample. Therefore, the values of correlation coefficients corrected for the vertebrae were calculated with each dimension and the values of corrected correlation coefficients for scale items with the scale as a whole, as shown in Table 4. 
Table 4. Correlation coefficients (corrected) values for the orientated targets scale items with the dimension to which it belongs to

\begin{tabular}{cccccc}
\hline & Mastery dimension & Performance dimension & \multicolumn{2}{c}{ Avoidance dimension } \\
\hline $\mathrm{N}$ & $\begin{array}{c}\text { (correlation with } \\
\text { dimension) }\end{array}$ & $\mathrm{N}$ & $\begin{array}{c}\text { (correlation with } \\
\text { dimension) }\end{array}$ & $\begin{array}{c}\text { (correlation with } \\
\text { dimension) }\end{array}$ \\
\hline 1 & 0.54 & 8 & 0.65 & 15 & 16 \\
2 & 0.75 & 9 & 0.43 & 17 & 0.86 \\
3 & 0.52 & 10 & 0.48 & 18 & 0.52 \\
4 & 0.58 & 11 & 0.73 & 19 & 0.65 \\
5 & 0.49 & 12 & 0.54 & 20 & 0.77 \\
7 & 0.80 & 13 & 0.81 & 21 & 0.68 \\
\end{tabular}

The data in Table 4 indicate that the correlation coefficients values of the scale items ranged between 0.43 and 0.86 . The values of the correlation coefficients of the items of performance dimension were ranged between 0.49 and 0.80 . The values of correlation coefficients for performance dimension ranged from 0.43 and 0.81 . As for the avoidance performance dimension, the correlation coefficients of the items ranged from 0.50 to 0.86 , all of which are statistically significant.

\subsubsection{Reliability of the Scale}

Abu Ghazal et al. (2013) verified the reliability coefficient of the Cronbach Alpha method on a survey sample. The internal consistency coefficient of the scale as a whole was 0.65 , and for the mastery dimension (0.79) and the performance dimension (0.71), and to the avoidance performance dimension $(0.61)$, which are acceptable indicators of reliability.

In the current study, the researcher verified the reliability of the scale in two ways: the first by applying it to an exploratory sample of 48 students, and the internal consistency coefficient was calculated using alpha Cronbach for the dimensions, these values ranging between 0.79 and 0.88 and 0.83 , The second method was the stability of reliability by applying it to the same exploratory sample. It was re-applied two weeks after the first application. These values ranged between 0.84 and 0.91 and the tool as a whole was 0.87 . The researcher believes that these values are suitable for using the list for the purposes of the current study, and Table 5 shows that.

Table 5. Internal consistency coefficient according to Alpha Cronbach formula and repetition reliability

\begin{tabular}{llllc}
\hline & \multicolumn{3}{c}{ Dimensions } & \multirow{2}{*}{ Scale as a whole } \\
\cline { 2 - 4 } & mastery & Performance & Avoidance & \\
\hline Cronbach Alpha & 0.83 & 0.79 & 0.88 & 0.83 \\
Repetition stability & 0.86 & 0.84 & 0.91 & 0.87 \\
\hline
\end{tabular}

\subsubsection{Correction of the Scale}

The scale consists of 21 paragraphs, consisting of a five-point scale $(5=$ very large, $4=$ large, $3=$ medium, $2=$ low, $1=$ very low), divided into three dimensions: mastery goals' dimension and it has 7 Paragraphs, performance goals dimension and it has (9) paragraphs, avoidance goals dimension and it has 5 paragraphs.

\subsection{Study Procedures}

To achieve the objectives of the study, the tools of the study were prepared in the final form after verifying the indicators of its validity and reliability, and then the scales were distributed to the students in the classrooms in April of the academic year 2017-2018, and they were given a general idea of the objectives and importance of the study, and the instructions relating the scale used was explained. They were assured that their participation was voluntary and that the statements they made would be treated in strict confidence and would be used for scientific research purposes. It should be noted that the instructions did not indicate that the scale deals with academic self-regulation, self-esteem, and goal orientations, so as not to affect the credibility of the participants' response, but merely to point out that these measures are related to personality traits. Students had to fill the scale for about 30 minutes. 


\subsection{Statistical Methods}

To know the level of both academic self-regulations, self-esteem, and goal orientations, arithmetical averages and standard deviations were calculated, to determine gender differences on the scale of self-regulation, self-esteem, goal orientations were used to determine the relationship between academic self-regulation and self-esteem, and goal orientation. Pearson correlation coefficients were calculated.

\subsection{Study Variables}

1) Independent variables: It includes the sex variable and has two categories (males, females).

2) Dependent variables: It includes variable academic-self organization, self-esteem, and goal orientations.

\section{Results}

Below are the results for each of the questions that the study attempted to answer.

First question: What is the level of (academic self-regulation, self-esteem, goal orientation) among a sample of university students in Jordan?

To answer this question, the arithmetical averages and standard deviations of the students' grades were calculated according to the criteria used in the study, as in Table 6.

Table 6. The arithmetical averages and the standard deviations of the grades of the students on the scales used

\begin{tabular}{llll}
\hline Scale & Mean & Standard deviation \\
\hline Academic self-organization & 2.56 & 0.74 \\
\hline Self-esteem & 2.89 & 0.86 \\
\hline \multirow{3}{*}{ Scale of oriented goals } & Mastery & 3.35 & 0.77 \\
\cline { 2 - 4 } & Performance & 3.54 & 0.71 \\
\cline { 2 - 4 } & Avoidance & 3.18 & 0.82 \\
\hline Scale as a whole & & 3.36 & 0.73 \\
\hline
\end{tabular}

Table 6 shows that students possess an average level of academic self-organization, with an average of 2.56. The students own an average level of self-esteem, where the mean reached 2.89. It is also noted that students have an average level of goal orientation, with a total mean of 3.34. In the dimensions, it is noted that the performance dimension came in first place with an average of 3.54 , and then followed by mastery dimension with an average of 3.35. Finally, avoiding dimension with an average of 3.18, all of which came at an average level.

Second question: Are there statistically significant differences in the level of academic self-regulation, self-esteem, goal orientation (due to gender variable in a sample of university students in Jordan?

To answer this hypothesis, the averages, standard deviations and T-test of the students' scores were calculated on the measures used, and this is shown in Table 7.

Table 7. The results of the T-test for the differences between the average scores of the educational track and the scales used

\begin{tabular}{|c|c|c|c|c|c|}
\hline Dimensions & & Mean & Standard deviation & $\mathrm{T}$ value & Sig \\
\hline \multirow{2}{*}{ Academic self-organization } & Male & 3.21 & 0.76 & \multirow{2}{*}{6.75} & \multirow{2}{*}{$* 0.000$} \\
\hline & Female & 3.40 & 0.71 & & \\
\hline \multirow{2}{*}{ Self-esteem } & Male & 3.15 & 0.81 & \multirow{2}{*}{7.68} & \multirow{2}{*}{$* 0.000$} \\
\hline & Female & 3.27 & 0.75 & & \\
\hline \multirow{2}{*}{ Mastery } & Male & 3.13 & 0.77 & \multirow{2}{*}{5.81} & \multirow{2}{*}{$* 0.000$} \\
\hline & Female & 3.32 & 0.68 & & \\
\hline \multirow{2}{*}{ Performance } & Male & 3.41 & 0.74 & \multirow{2}{*}{7.17} & \multirow{2}{*}{$* 0.000$} \\
\hline & Female & 3.29 & 0.82 & & \\
\hline \multirow{2}{*}{ Avoidance } & Male & 3.08 & 0.86 & \multirow{2}{*}{6.24} & \multirow{2}{*}{$* 0.00$} \\
\hline & Female & 3.23 & 0.91 & & \\
\hline
\end{tabular}

$* \mathrm{P}<0.0001$. 
Table 7 shows that the value of $(t)$ for the self-regulation of the academic level was 6.75 and statistically significant $(\mathrm{P}<0.0001)$, and it is clear that the average female score is higher than that of males. And that the value of $(\mathrm{t})$ of the self-assessment scale as a whole was 7.68 with a statistical significant $(\mathrm{P}<0.0001)$, and it is clear that the average female score is higher than that of males, and that the value of $(t)$ for the mastery dimension was 5.81 with a statistical significant $(\mathrm{P}<0.0001)$. The average female scores were higher than the average of males; while in the performance dimension $(\mathrm{t}=7.17)$ with a statistical significant of $(\mathrm{P}<0.0001)$.

The average male score was higher than the female average; finally, the performance dimension was 6.24 with a statistical significant $(\mathrm{P}<0.0001)$, it is clear that the mean of the females is higher than the males.

Third Question: Is there a statistically significant relationship between academic self-organization and self-esteem and goal orientations among a sample of university students?

To verify this hypothesis, Pearson correlation coefficients were calculated between the scores of the students on the self-academic scale and their scores on the self-esteem scale, as shown in Table 8.

Table 8. Correlation coefficients between students' grades on the dimensions of the academic self-regulation scale and their grades on self-esteem and oriented goals scales

\begin{tabular}{lcccc}
\hline Variable & Total sample & Males & Females & $\mathrm{Z}$ value \\
\hline Self-esteem & $* 0.42$ & $* 0.24$ & $* 0.55$ & $* 5.06$ \\
\hline Oriented targets & $* 0.36$ & $* 0.44$ & $* 0.27$ & $* 2.65$ \\
\hline
\end{tabular}

$* \mathrm{~F}<0.01$.

Table 8 shows that there is a statistically significant positive relation between the academic self-regulation scale and self-esteem, and that this relation in the female path is stronger than that of males. And that there is a statistically significant positive relationship between the academic self-regulation scale and the goals orientations, and that this relationship among males is stronger than that of females.

\section{Discussion}

The results indicate that there is an average level of academic self-organization. The researcher attributes this to the lack of a comfortable academic educational atmosphere in which students feel safe and free to express their ideas, in addition to the lack of receptivity and the opening of channels of communication with them, especially students with low academic level, as well as the lack of knowledge of the sources of knowledge and the ability to use it, and the lack of availability of skill in the organization of positions and academic and educational activities and have the ability to follow the instructions and rules flexibly and away from the inquisitiveness and openness to new experiences and information and do not have the initiative to solve problems and completion of business.

While the results indicate that the members of the sample having an average level of self-esteem, where the researcher suggests that this is due to lack of efficiency in speaking or acting attitudes, and the sense of embarrassment and shyness and the weakness of communicating with others, and conducting isolation behavior and lack of participation and required classroom interaction. In addition to repeated self-comparisons of other students, and the researcher believes that this also due to experiences and feelings of a sad nature in his life and thinking, and the tendency to focus on the weaknesses and shortcomings that he has and weak consideration of the pros and developing it.

The results also indicate that the students obtained an average level of orientation of the goals, where the researcher believes that the repeated experiences and failed experiences in academic life and lack of ability to avoid them in addition to the weakness of self-esteem, Creating a weakness of feeling and ability to direct goals, in addition to the lack of possession of a full view of their abilities and sense of self-esteem leading them to direct their very low-level goals to try to get rid of the failures and academic difficulties that face them.

The female superiority of males in academic self-organization is due to the fact that females are perfect listeners to instructions, meticulous and follow-up, as well as the self-discipline that accompanies them in the study stages in general and in the university stage in particular. The social and cultural factors that encourage girls to study, and their efforts to focus on the understanding of subjects, make them superior and organize themselves more than males, and that the female focus on the study significantly unlike the males who focus on other things in their lives, and dispersed their concentration in academic life.

The researcher suggests that the superiority of females in self-esteem of males due to that they have a positive 
outlook for their own, and tend to achieve their goals more complete, in addition to the awareness of parents in the process of socialization and development, which reflected on them and the development of their personalities. Social and economic variables may force women to attain a good level of self-esteem to secure their lives, reach their ambitions, attain financial independence, and raise the status of females in society. Their assertion of their right to leadership positions has earned them self-esteem and appreciation more than males. The results of this study differ with the study of Abu Ghazal et al. (2013), and the study of Collison et al. (2016), which showed differences in self-esteem in favor of males.

The researcher points to the superiority of females to males in the mastery dimension that they develop their skills in achieving goals and master it and that they have the motivation to achieve the best results of the goals that have been developed, they are also more patient in their stamina to reach the goal and tend to spend more time handling tasks. The superiority of males over females in the performance dimension is that they tend to accomplish tasks and achieve excellence and success without considering the level of mastery, they tend to achieve the goal they seek without providing their minimum needs, they focus on maintaining a good image of others, and they are superior to others. While the superiority of females in the avoidance dimension that they tend to avoid failure and move away from experiments that cause loss of the target, as they have perceptions of self-efficacy in which they try to maintain their status, their reputation and their gains, and to refrain from describing them as failures and disabled in front of others, thereby diminishing their self-esteem. The results of this study are consistent with the study of Abu Ghazal et al. (2013) which indicated differences in the direction of performance-avoidance for females, and differ from the study of Abu Ali (2015), which indicated differences in the mastery dimension in favor of the males, and the absence of statistically significant differences in the performance dimension and avoidance dimension attributed to the impact of gender variable.

The researcher explains the result of the correlation of self-esteem with academic self-organization that the sense of self-esteem is conducive to achieving and maintaining academic self-organization, the positive attitudes of the students toward self-esteem reinforce the self-motivation that creates an academic atmosphere conducive to self-organization. Students who organize themselves academically have the ability to build positive attitudes and begin to deal with others. The self-satisfied students have a behavioral ability to build structured learning environments that increase their ability to achieve greater academic self-organization. The result of this study is consistent with Sakiz (2011), which points out that the goal-oriented orientation was positively and statistically correlated with the beliefs of academic self-efficacy and student behavior, and the study of Johnson et al. (2009), which revealed a positive correlation between each of the learning objectives and performance goals and self-esteem, which revealed a statistically significant correlation between academic achievement and self-esteem. The result of this study differs with Johnson et al. (2009), which revealed a significant inverse relationship between performance- avoidance goals and self-esteem.

The researcher believes that the low motivation to achieve the goals is to create a level of low academic self-regulation, thus, the one who uses methods of academic self-organization that has the ability and flexibility to achieve positive results that increase motivation and overcome obstacles that hinder the achievement of the goals set, so academic self-regulation guides motivation and entrepreneurship that will enable success. The researcher believes that the focus on those who use an academic self-organization have a clear focus on the goals, they prefer to use skills that challenge their abilities, as well as having positive attitudes towards organization and goal-making.

\section{Recommendations}

In light of the findings of the study, the researcher recommends the following:

1) Encouraging students to further academic self-organization for its benefits on aspects of life, especially the academic aspect.

2) Work on raising the awareness of the family about the importance of encouraging children to adopt goals and develop their self-esteem.

3) Conducting training workshops for undergraduate students on how to organize academic and goal orientations.

4) Teachers instruct students on ways to organize and focus on academic aspects.

5) Working on activating the educational extension services to guide students towards the direction of the goals.

\section{Suggestions}

- Conducting new studies on the academic self-regulation of the lack of Arab research on this variable. 
- Conducting studies on the variable of academic self-organization in other samples such as adolescence and different stages of study.

\section{References}

Abu Ali, A. (2015). The relationship between goals and metacognitive thinking of Yarmouk University students (Unpublished master thesis). Yarmouk University, Irbid, Jordan

Abu Ghazal, M., Al-Hamouri, F., \& Al-Ajlouni, M. (2013). Attitudes of Objectives and their Relation to Self Esteem and Academic Accreditation of Yarmouk University Students in the Hashemite Kingdom of Jordan. Educational Journal-Kuwait, 27(108), 111-154.

Akhtar, J., \& Mahmood, N. (2013). Development and validation of an academic self-regulation scale for university students. Journal of Behavioural Sciences, 23(2), 37-45. https://doi.org/10.1037/t34538-000

Ames, C. (1992). Classrooms: Goals, structures, and student motivation. Journal of Educational Psychology, 84(3), 261-271. https://doi.org/10.1037/0022-0663.84.3.261

Baumeister, R., \& Bushman, B. (2008). Social Psychology \& Human Nature. Belmont, CA: Thomson Higher Education.

Baumeister, R., \& Vohs, K. (2004). Sexual economics: Sex As female resource for social exchange in heterosexual interactions. Personality and Social Psychology Review, 8, 339-363. https://doi.org/10.1207/s15327957pspr0804_2

Baumeister, R., \& Vohs, K. (2007). Self-regulation, ego depletion, and motivation. Social and Personality Psychology Compass, 1, 1-14. https://doi.org/10.1111/j.1751-9004.2007.00001.x

Branden, N. (2001). The psychology of self-esteem. New York: Bantam.

Collison, D., Banbury, S., \& Lusher, J. (2016). Relationships between age, sex, self-esteem and attitudes towards alcohol use amongst university students. Journal of Alcohol and Drug Education, 60(2), 16-34.

DeGeest, D., \& Brown, K. (2011). The role of goal orientation in leadership development. Human Resource Development Quarterly, 22(2), 157-175. https://doi.org/10.1002/hrdq.20072

Fan, J., Meng, H., Billings, R., Litchfield, R., \& Kaplan, I. (2008). On the role of goal orientation traits and self-efficacy in the goal-setting process: Distinctions that make a difference. Human Performance, 21, 354-382. https://doi.org/10.1080/08959280802347122

Harackiewicz, J., Barron, K., \& Elliot, A. (1998). Rethinking achievement goals: When they are adaptive for college students and why? Educational Psychologists, 33, 1-21. https://doi.org/10.1207/s15326985ep3301_1

Hendricks, J., \& Payne, S. (2007). Beyond the Big Five: Leader goal orientation as a predictor of leadership effectiveness. Human Performance, 20, 317-343.

Jaradat, A. (2006). The relationship between self-esteem and irrational trends among university students. The Jordanian Journal of Educational Sciences, 2(3), 143-153.

Johnson, V., Radosevich, D., \& Radosevich, D. (2009). Implicit and explicit self-esteem as antecedents of the goal orientation and cognitive engagement relationship. Review of Business Research, 9(2), 164-175.

Kapikiran, S., \& Kapikiran, N. (2016). Optimism and psychological resilience in relation to depressive symptoms in university students: Examining the mediating role of self-esteem. Educational Sciences: Theory \& Practice, 16(6), 2087-2110. https://doi.org/10.12738/estp.2016.6.0107

Kaur, H., \& Kaur, K. (2014). A study of adolescent's strengths and difficulties and academic self regulation. Indian Journal of Health and Wellbeing, 5(8), 913-917.

Lindsay, J., \& Scott, W. (2005). Dysphoria and self-esteem following an achievement event: Predictive validity of goal orientation and personality style theories of vulnerability. Cognitive Therapy and Research, 29(6), 769-785. https://doi.org/10.1007/s10608-005-9637-6

Matuga, J. (2009). Self-regulation, goal Orientation, and academic achievement of secondary students in online university courses. Educational Technology \& Society, 12(3), 4-11.

Ormrod, J., \& Jones, B. (2009). Essentials of educational psychology, Big ideas to guide effective teaching. Cambridge: Pearson for publishing.

Orth, U., \& Robins, R. W. (2014). The development of self-esteem. Current Directions in Psychological Science, 


\section{3(5), 381-387. https://doi.org/10.1177/0963721414547414}

Panadero, E., \& Alonso-Tapia, J. (2014). How do students self-regulate? Review of Zimmerman's cyclical model of self-regulated learning. Anal. Psicol, 30(2), 450-462. https://doi.org/10.6018/analesps.30.2.167221

Payne, S., Youngcourt, S., \& Beaubien, J. (2007). A meta-analytic examination of the goal orientation nomological net. Journal of Applied Psychology, 92, 128-150. https://doi.org/10.1037/0021-9010.92.1.128

Rosenberg, M. (1965). Society and the adolescent self-image. Princeton, NJ: Princeton University Press. https://doi.org/10.1515/9781400876136

Sahloul, M. (2009). The self-organized learning strategy and the thinking methods that characterize Sana'a University students with high and low achievement goals (Unpublished $\mathrm{PhD}$ dissertation). Yarmouk University, Irbid, Jordan.

Sakiz, G. (2011). Mastery and performance approach goal orientations in relation to academic self-efficacy beliefs and academic help seeking behaviors of college students in turkey. Educational Research, 2(1), 771-778.

Sarmini, M. (2016). Attitudes of objectives and their relationship to the five major factors of personality in Yarmouk University students in the light of some variables (Unpublished master thesis). Yarmouk University, Irbid, Jordan.

Sayette, M. (2004). Self-regulatory failure and addiction. In R. F. Baumeister, \& K. D. Vohs (Eds.), Handbook of self-regulation: Research, theory, and applications (pp. 447-465). New York: Guilford Press.

Schmeichel, B., \& Baumesiter, R. (2004). Self-regulatory strength. In R. F. Baumeister, \& K. D. Vohs (Eds.), Handbook of Self-regulation: Research, Theory, and Applications. New York: Guilford Press.

Shabaily, F., \& Watban, M. (2016). Achievement goals, self-esteem and perseverance as a predictor of the future goals of the students of Qassim University. Journal of Educational Sciences, 28(1), 43-68.

Zimmerman, B. (2000). Attaining self-regulation: A social cognitive perspective. In M. Boekaerts, P. R. Pintrich, \& M. Zeidner (Eds.), Handbook of Self-Regulation (pp. 13-35). San Diego: Academic Press.

\section{Copyrights}

Copyright for this article is retained by the author(s), with first publication rights granted to the journal.

This is an open-access article distributed under the terms and conditions of the Creative Commons Attribution license (http://creativecommons.org/licenses/by/4.0/). 